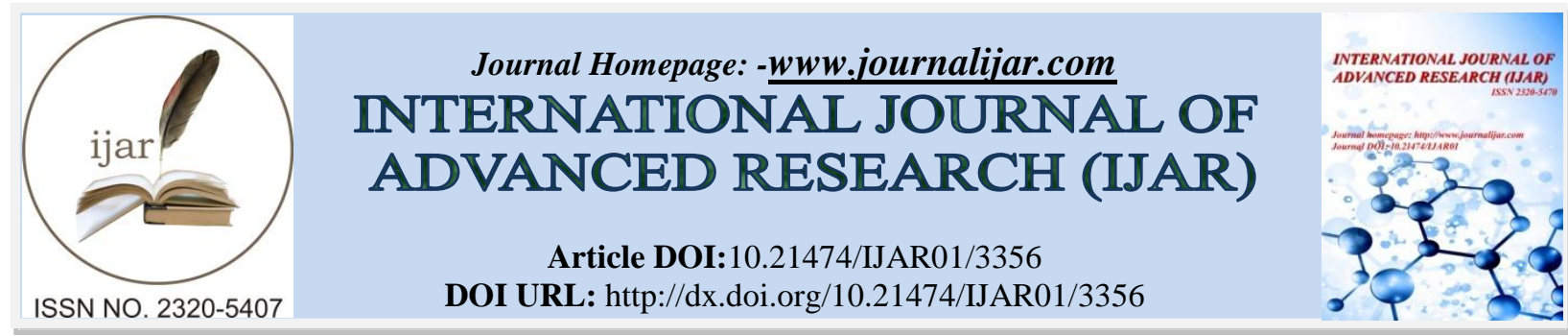

RESEARCH ARTICLE

\title{
BURN INJURIES AND ASSOCIATED CAUSES IN AL KHARJ PROVINCE OF SAUDI ARABIA: ARE THEY PREVENTABLE?
}

\author{
Dr. Anthony Morgan, Dr. Adel Mohammed Bin Sultan, Dr. Abdullah Mussad Al Harbi, Dr. Saad \\ Mohammed Aljuhayyim, Dr. Omar Abdullah Al Hatlan and Mr. Yazeed Aldhfyan.
}

\section{Manuscript Info}

Manuscript History

Received: 20 December 2016

Final Accepted: 29 January 2017

Published: February 2017

Key words:-

Mechanism of burns,Burn causes,

Traumatic burns, Saudi Arabian population.

\section{Abstract}

Introduction:Currently, studies investigated burn injuries and their causes in Saudi Arabia mainly focused on pediatric patients, while epidemiology of burns among the adult population required more exploration. Therefore, the purpose of this study was to investigate the pattern of burns and associated factors among both children and adults in one of the largest Saudi Arabian province.

Methods: This is a surgical audit type study included patients admitted with the burns to the surgical department of King Khaled Hospital in Al Kharj province of Saudi Arabia. The medical records of 60 patients with burn injuries, admitted from 2010 to 2015 inclusive, were reviewed for demographic factors, the pattern of burns, the severity of burn injuries and associated trauma injury severity score (ISS), the length of hospital stay, the types of burns, and the most common body locations. Descriptive statistics including frequencies, percentages, means, and standard deviations were demonstrated in tables and graphs. Inferential statistics were used to detect significant study associations. The $P$ values less than 0.05 were considered significant.

Results: This study included 60 patients, where 57\%were non-Saudis and the majority were adult males. The most affected body parts were the upper extremities followed by lower extremities and the head. The most common types of burns where hot liquid burns (43.3\%), followed by flame burns $(28.3 \%)$. The significant correlations were found between the mechanism of burn and patient's gender and age. The burns area was directly related to the length of hospital stay and correlated well to the age $(\mathrm{p}=0.037)$.

Conclusion: The hot liquid burns are the most common types of burns followed by the flame burns. The hot liquid burns were commonly affecting Saudi nationality, children and female gender. The areas of burns are well correlated to the age of affected patients and the length of hospital stay.

Copy Right, IJAR, 2017,. All rights reserved.

\section{Introduction:-}

Burn defined as a traumatic injury, which occurs when skin or other underlying tissues are damaged by the mechanism of direct thermal, chemical, electrical or frictional exposure. ${ }^{1}$ The type of burn is dependent on the age factor, where the most common burns in children are the results of direct hot fluid and skin contact, while flame exposure, electrical and frictional burns are most common among adults. ${ }^{2}$ According to the depth of the injury, burns 
are classified into four degrees, although most of the times the burn injury include more than the first degree. The first degree is defined by superficial or epidermal burn, which may be equal by the clinical presentation to the sunburn. The second degree constituted of partial burning of skin thickness. The third degree burn involves the full thickness of skin, while the fourth degree involves the underlying tissues or organs. ${ }^{3}$

The (World Health Organization) WHO estimated the global incidence of burn injuries to be 110/100,000 per year. ${ }^{4}$ Saudi Arabia, as well as many other developing countries, is undergoing a period of changes in regards to transformation from non-communicable problems to the pattern of chronic diseases and trauma, which is more common for industrial communities. ${ }^{5}$ Burns representing acommon type of domestic trauma, that have been increased due to urbanization and introduction of technologies and complex electrical, and mechanical equipments to the daily live. ${ }^{6}$

In Saudi Arabia, the incidence rate of burns among children was shown by Alharthy et al. to be 494/100,000 per year. They found that $16 \%$ of children, attended hospitals with burns, had more than $10 \%$ of total body surface area (TBSA) involved. The most common causes of burns among Saudi children were the hot liquids burns followed by flame injuries. ${ }^{7,8}$ This was supported by study conducted among children in Makah city, which found that majority of burn injuries were related to the direct hit exposure by high temperature fluids. ${ }^{9}$ Only one study, conducted by Jamal et al., in Jeddah city, investigateda wide range of age groups in relation to the patterns of burns. ${ }^{10}$ Thus, current study aimed to investigate the pattern of burns and associated factors among both children and adults in one of the largest provinces of Saudi Arabia based on the local trauma registry.

\section{Methods:-}

This retrospective audit study design included patients admitted with all types of burns injuries in one of the teaching university affiliated hospital in the Kharj province of Saudi Arabia. The medical records of patients collected over the period of the last five years, presented and admitted to the surgical department with burn injuries, were reviewed for the collection of demographic factors, pattern of burns, length of the hospital stay, mechanisms of burns and parts of body locations with TBSA involved. The confidentiality of the patients was ensured through the anonymous data entry from medical records. The data were analyzed using descriptive statistics such as frequencies, percentages, means and standard deviations. The chi-square test was used to identify significant differences between demographical variables and causes of burns. The independent t-test was used to identify significant differences in groups of numerical variables. Pearson's correlation was used to identify the relation between the age of theinjured with burns and the length of hospitalization. The $\boldsymbol{p}$ values less than 0.05 were considered as statistically significant.

\section{Results:-}

Medical records of 60 patients were included in this study, showing that $56.7 \%$ were non-Saudis. All patients were exposed to different mechanisms of burn withvarious body parts and the total areaaffected.The majority of the patients (70\%) were males and 30\% were females respectively. Mean of age of burn victims was $21 \pm 15.5$ ranging from 1 year to 64 years old. $25 \%$ of the patients with burns were under 5 years old children and near $38 \%$ were under the age of 16 years old, while the rest were adults as shown in Table 1.

Table 1:-Distribution of demographic factors.

\begin{tabular}{|c|c|c|c|}
\hline \multicolumn{2}{|c|}{ DEMOGRAPHIC FACTORS } & Patients $(\mathrm{n})$ & $\%$ \\
\hline \multirow{2}{*}{ Gender } & Male & 42 & 70.0 \\
\cline { 2 - 4 } & Female & 18 & 30.0 \\
\hline \multirow{3}{*}{ Nationality } & Saudi & 26 & 43.3 \\
\cline { 2 - 4 } & Non-Saudi & 34 & 56.7 \\
\hline \multirow{3}{*}{ Age groups } & $<5$ years old & 15 & 25.0 \\
\cline { 2 - 4 } & $5-10$ years old & 5 & 8.3 \\
\cline { 2 - 4 } & $11-16$ years old & 3 & 5.0 \\
\cline { 2 - 4 } & $>16$ years old & 37 & 61.7 \\
\hline
\end{tabular}

The distribution of burns in this study demonstrated, that the majority (70\%) of them had the second-degree burns followed by the third and first-degree burns in $16.7 \%$ and $13.3 \%$ respectively. The most affected body locations were the upper limbs (63.3\%) followed by the lower limbs and the head, which accounted for 50\%, and $46.7 \%$ respectively. This reflecting that many burn areas have affected more than one site in the body. The chest, neck, and 
back areas were involved in $20 \%, 16.7 \%$, and $15 \%$ of burns respectively, while the least affected sites were genitalia and abdominal areas. No burnswere identified involving the pelvic area in this study. The majority of the patients had more than one location affected by burn injury and $68.3 \%$ had burn with $>10 \%$ of TBSA was involved. There was no mortality reported. Table 2. (Graph 1 )

Table 2:-Patterns and locations of burns among study subjects ( $\mathrm{n}=60)$.

\begin{tabular}{|c|c|c|c|}
\hline \multicolumn{2}{|c|}{ Classification, body parts and area of burns } & Patients (n) & $\%$ \\
\hline \multirow{2}{*}{ Degree of burn } & I degree & 8 & 13.3 \\
\cline { 2 - 4 } & II degree & 42 & 70.0 \\
\cline { 2 - 4 } & III degree & 10 & 16.7 \\
\hline Head & & 28 & 46.7 \\
\hline Neck & & 10 & 16.7 \\
\hline Chest & & 12 & 10.0 \\
\hline Abdomen & & 6 & 6.7 \\
\hline Genitalia & & 4 & 15.0 \\
\hline Back & & 9 & 63.3 \\
\hline Upper limb burn & & 38 & 50.0 \\
\hline Lower limb burn & & 30 & 31.7 \\
\hline TBSA\% & $>10 \%$ & 19 & 68.3 \\
\hline
\end{tabular}

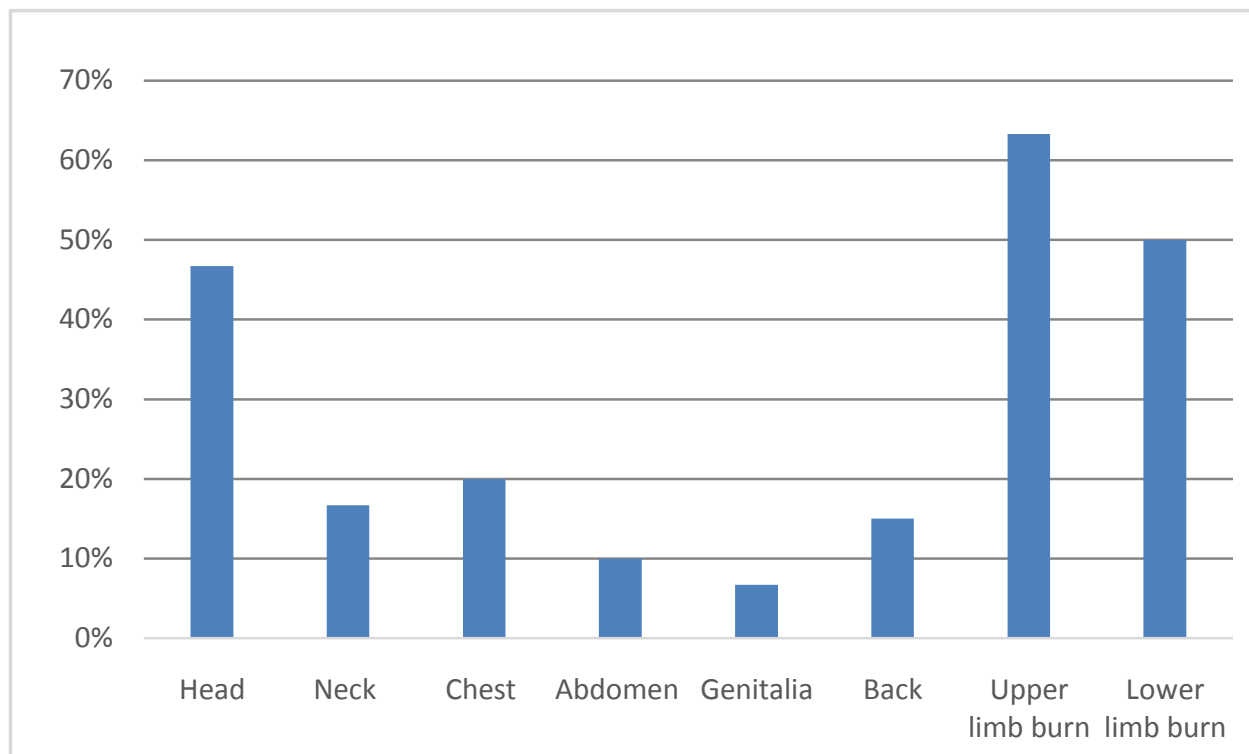

Graph 1:- Body parts affected by burns

The most common cause of burns was from contact with hot fluids (43.3\%), followed by the flame burns (28.3\%), electrical (18.3\%), chemical (8.3\%) and frictional burns (1.7\%) respectively, as reflected in Graph 2. 


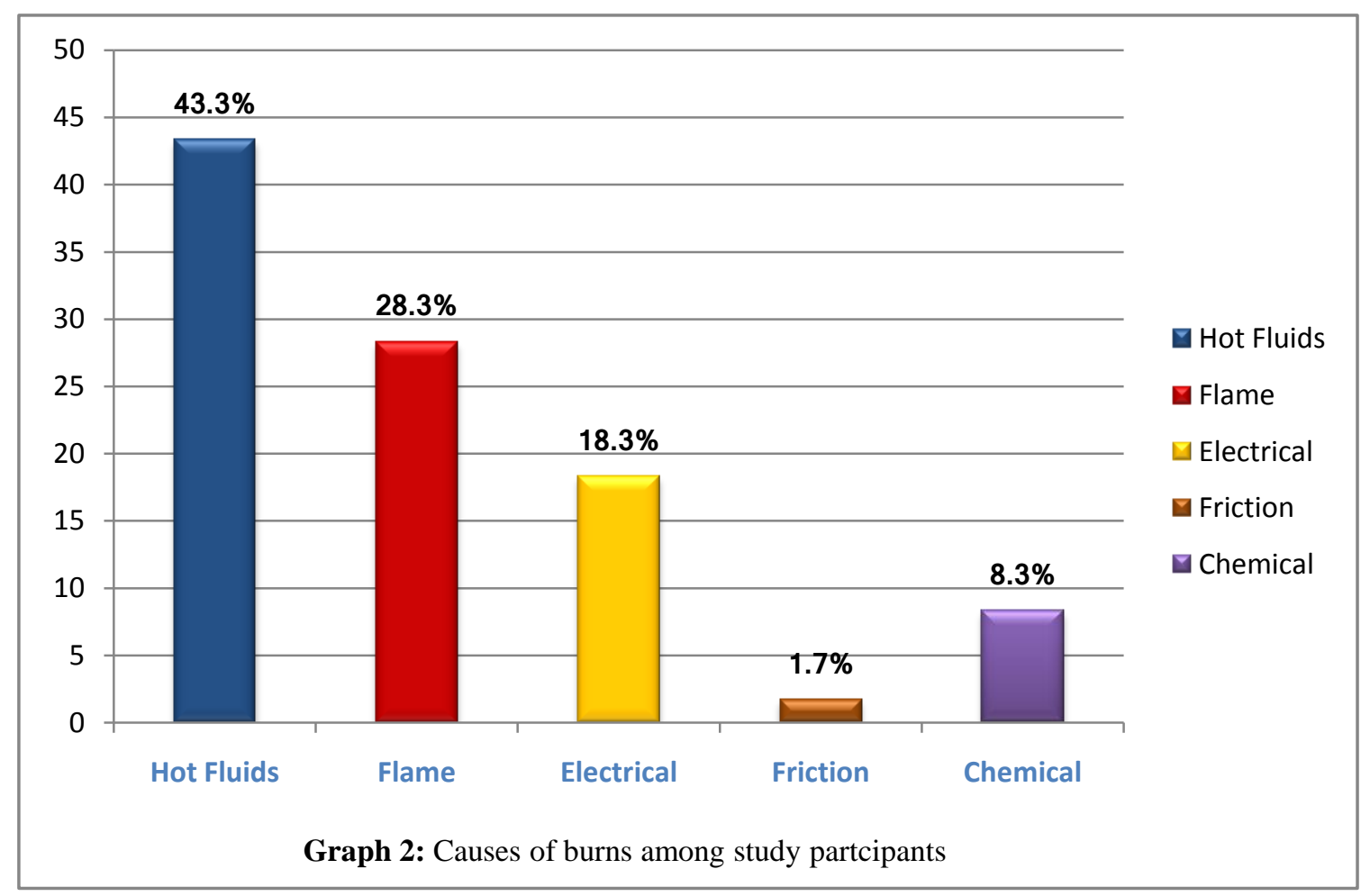

The significant correlations were identified between the patient's nationality, gender and age to the causes of burns. $69.2 \%$ of the Saudis were affected by hot fluids burns in comparison to $23.5 \%$ of non-Saudi $(\mathrm{p}=0.001)$. A significantly higher percentage of women (77.8\%) had hot fluids burns compare to men, where only $28.6 \%$ had burns related to hot fluid exposure. Children under the age of 5 had a significantly higher prevalence (93.3\%) of hot fluids burns. No women had electrical or frictional burns and only one had chemical burn. The children and adolescents $(<16$ years old) had a significantly higher prevalence $(82.6 \%)$ of hot fluid burns in comparison to adult patients (Table 3, Graph 3). The mean length of stay was $7 \pm 5$ days and ranging from 1 day to 1 month, depending on the severity of burn and TBSA. The correlation between TBSA and the length of hospital stay was significantly increased when the patients had more than $10 \%$ TBSA affected by burns $(\mathrm{p}=0.037)$.

Table 3:-Correlation between demographic factors and causes of burn.

\begin{tabular}{|c|c|c|c|c|c|c|}
\hline \multicolumn{2}{|c|}{ Demographic factors } & \multicolumn{5}{|c|}{ Causes of burn } \\
\hline & & Hot fluid & Flame & Electrical & Friction & Chemical \\
\hline \multirow[t]{2}{*}{ Nationality } & Saudi & $\begin{array}{c}18 \\
(69.2 \%)\end{array}$ & $\begin{array}{c}6 \\
(23.1 \%)\end{array}$ & $\begin{array}{c}0 \\
(0.0 \%)\end{array}$ & $\begin{array}{c}1 \\
(3.8 \%)\end{array}$ & $\begin{array}{c}1 \\
(3.8 \%)\end{array}$ \\
\hline & Non-Saudi & $\begin{array}{c}8 \\
(23.5 \%) \\
\end{array}$ & $\begin{array}{c}11 \\
(32.4 \%) \\
\end{array}$ & $\begin{array}{c}11 \\
(32.4 \%) \\
\end{array}$ & $\begin{array}{c}0 \\
(0.0 \%) \\
\end{array}$ & $\begin{array}{c}4 \\
(11.8 \%) \\
\end{array}$ \\
\hline \multirow[t]{2}{*}{ Gender } & Male & $\begin{array}{c}12 \\
(28.6 \%)\end{array}$ & $\begin{array}{c}14 \\
(33.3 \%)\end{array}$ & $\begin{array}{c}11 \\
(26.2 \%)\end{array}$ & $\begin{array}{c}1 \\
(2.4 \%)\end{array}$ & $\begin{array}{c}4 \\
(9.5 \%)\end{array}$ \\
\hline & Female & $\begin{array}{c}14 \\
(77.8 \%)\end{array}$ & $\begin{array}{c}3 \\
(16.7 \%)\end{array}$ & $\begin{array}{c}0 \\
(0.0 \%)\end{array}$ & $\begin{array}{c}0 \\
(0.0 \%)\end{array}$ & $\begin{array}{c}1 \\
5.6 \%\end{array}$ \\
\hline \multirow[t]{2}{*}{ Age group } & $<16$ years old & $\begin{array}{c}19 \\
(82.6 \%)\end{array}$ & $\begin{array}{c}2 \\
(8.7 \%)\end{array}$ & $\begin{array}{c}1 \\
(4.3 \%)\end{array}$ & $\begin{array}{c}0 \\
(0.0 \%)\end{array}$ & $\begin{array}{c}1 \\
(4.3 \%)\end{array}$ \\
\hline & $>16$ years old & $\begin{array}{c}7 \\
(18.9 \%)\end{array}$ & $\begin{array}{c}15 \\
(40.5 \%)\end{array}$ & $\begin{array}{c}10 \\
(27.0 \%)\end{array}$ & $\begin{array}{c}1 \\
(2.7 \%)\end{array}$ & $\begin{array}{c}4 \\
(10.8 \%)\end{array}$ \\
\hline
\end{tabular}




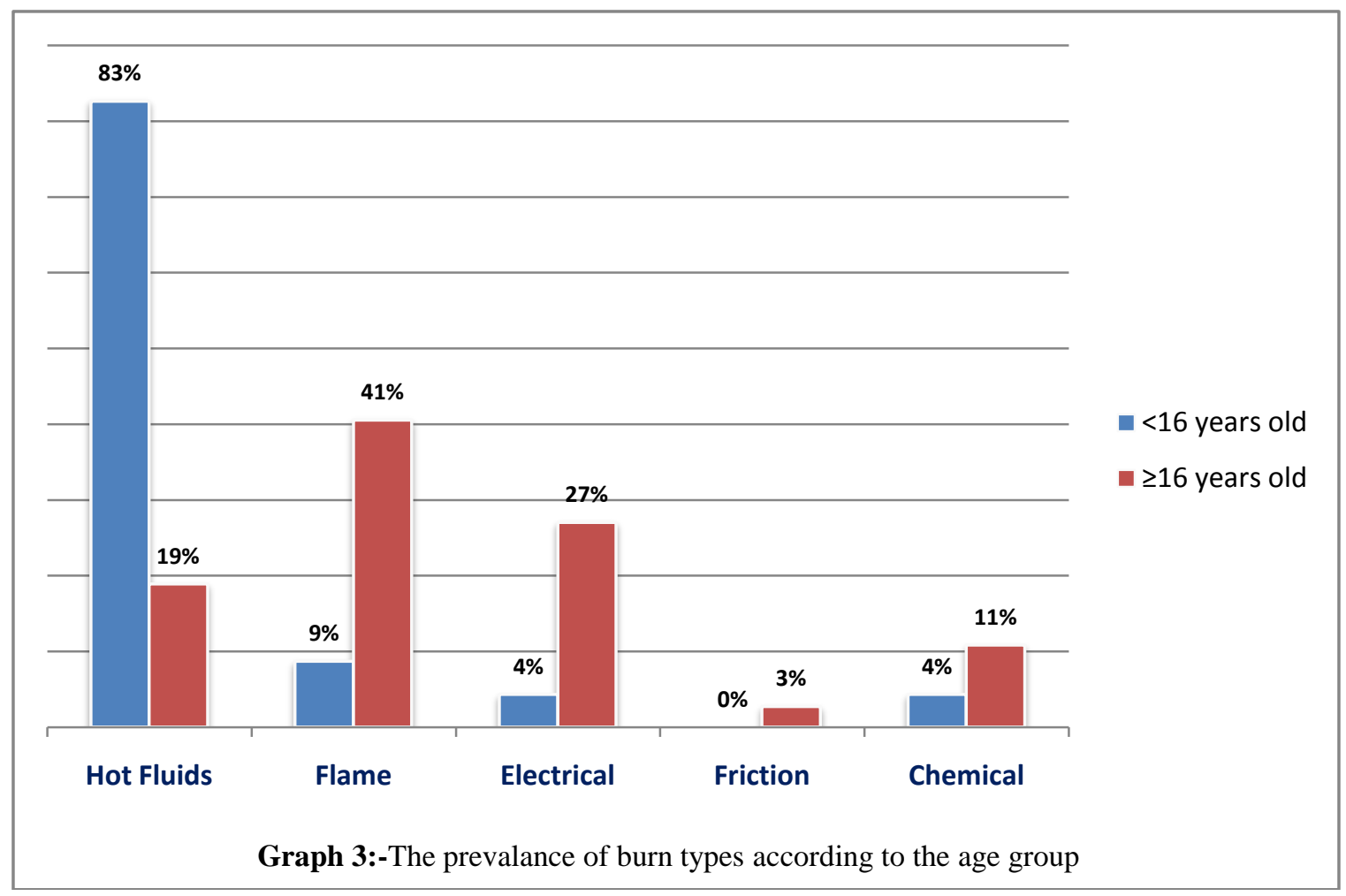

\section{Discussion:-}

The burns result not only a physical damage to the body surface, but also affecting the psychological well being of the affected patients. In addition, it has an very high impact on the socio-economic status in the community and large burden to the Health System of the society by the required medical and surgical treatments and long hospital stay. ${ }^{11}$

In modern communities, regardless of cultural and ethnic differences, children of young age mostly affected by the exposure of hot fluids and flames. However, increase in urbanization and industrial development leads to the higher incidence of burns related to advance technologies and exposure to high voltage electricity and work with complex mechanical equipment.

This study highlighted, that the majority of the patients $(70 \%)$ were males, where about $38 \%$ were under 16 years old. A Saudi study conducted by Mahaluximivala et al. found different characteristics of admitted patients with burns in AlQassim region, where $51 \%$ of patients were males and $41 \%$ where adults. ${ }^{12}$ Their results showed that the most affected sites of the burns were the upper limbs followed by lower limbs and the head. This was in agreement with Gangemi et al., where upper limbs were also found the most common site followed by the lower limbs, then the head and the neck. ${ }^{13}$

The findings of our study demonstrate, that the TBSA was significantly related to the length of the hospital stay, when the patients had more than $10 \%$ of TBSA. The findings reported by Iranian study where the mean admission time wasrelated to the burn size till, the peak of $60 \%$ were agreed with the present study findings. ${ }^{14}$ However, Lari $\mathrm{AR}$ et al, found that the length of hospital stay was declined when the burn area became more than $60 \%$, due to the increased mortality. In our study, the mean length of hospitalization was $7 \pm 5$ days, which is less than reported by other Saudi studies conducted in pediatric patients ${ }^{9,15}$ This could be attributed to a positive correlation found between pediatric age and shorter hospital stay, as children have atendency to stay in hospital less than adults.

In the present study, the most common cause of burns where burns caused by exposure to hot fluids (43.3\%), followed by flame, electrical, chemical and mechanical exposure. This is in agreement with findings showed by the Saudi study of Mahaluximivala et al., when hot fluids burns where the most common mechanism of injuries causing the burns in $40 \%$ of cases, followed by flame burns. ${ }^{12}$ The main contributory factor for this high prevalence of burns 
related to hot fluids is the traditional Arabic costume of preparation coffee and tea drinks in social events and the family gathers. This can be supported by the fact that, a significantly higher number of Saudi patients were affected by hot fluids burns in comparison to non-Saudis.

In the present study, hot fluid burns were significantly more common among women than men, which could be attributed to the traditional role of women in cooking and food preparation. No women had electrical or frictional burns and only one had chemical burn, due to traditionally no or little contacts with outdoor activities in the Saudi community in contrast with men, which made them more susceptible to flame, chemical and electrical burns.

In this study the high prevalence for children under the age of 5 to have hot fluid burn could be explained by the presence of the young children around the kitchen area close to their mother's, where the boiling water or hot food in preparation could be easily exposed to. Similar findings reported by other Saudi and Kuwaiti studies where similar culture traditions are practiced. ${ }^{9,17,18}$ In addition, a Turkish study found similar results for the high prevalence of burns among children. Due to the fast development of Saudi Arabia in relation to the buildings of the complex industrial infrastructure, we can see more injuries related to the electrical and mechanical burns. Also the high impact of the modernization in Saudi industries increasing the exposure of the working male population to chemicals and petroleum related products, which increasing chances for the flame burns. This explaining a relatively high volume of other causes of burns identified in our study.

Some limitations of this study include the short period of data collection due to the relatively recent trauma registries available.

\section{Conclusion:-}

The hot liquidsburns were the most common type of burn injuries followed by the flame exposure. Larger study is required for a more detailed look in relation to the outcome and correlations to the TBSA by various mechanisms of burn injuries.

\section{Conflict of interest:-}

No financial support was received for conduction of this study, and the investigators stated no conflict of interests.

\section{References:-}

1. Association AB. American Burn Association White Paper: Surgical management of the burn wound and use of skin substitutes2009.

2. Peck MD. Epidemiology of burns throughout the World. Part II: intentional burns in adults. Burns. 2012;38(5):630-637.

3. Mertens DM, Jenkins ME, Warden GD. Outpatient burn management. The Nursing clinics of North America. 1997;32(2):343-364.

4. Mathers C, Fat DM, Boerma JT. The global burden of disease: 2004 update: World Health Organization; 2008.

5. Othman N, Kendrick D. Epidemiology of burn injuries in the East Mediterranean Region: a systematic review. BMC public health. 2010;10(1):83.

6. Brusselaers N, Monstrey S, Vogelaers D, Hoste E, Blot S. Severe burn injury in Europe: a systematic review of the incidence, etiology, morbidity, and mortality. Critical care. 2010;14(5):R188.

7. Alharthy N, Al Mutairi M, AlQueflie S, et al. Pattern of burns identified in the Pediatrics Emergency Department at King Abdul-Aziz Medical City: Riyadh. Journal of natural science, biology, and medicine. 2016;7(1):16.

8. El Danaf A, Alshlash S, Filobbos P, Rasmi M, Salem S. Analysis of 105 patients admitted over a 2-year period to a modern burns unit in Saudi Arabia. Burns. 1991;17(1):62-64.

9. Gari AA, Al-Ghamdi YA, Qutbuddeen HS, Alandonisi MM, Mandili FA, Sultan A. Pediatric burns in Western Saudi Arabia. Saudi medical journal. 2012;33(10):1106-1110.

10. Jamal Y, Ardawi M, Ashy A, Merdad H, Shaik S. Burn injuries in the Jeddah area of Saudi Arabia: a study of 319 cases. Burns. 1989;15(5):295-298.

11. Finkelstein E, Corso PS, Miller TR. The incidence and economic burden of injuries in the United States: Oxford University Press, USA; 2006.

12. Mahaluxmivala S, Borkar A, Mathur A, Fadaak H. A retrospective study of etiopathological and preventive factors in a burns unit in Saudi Arabia. Burns. 1997;23(4):333-337. 
13. Gangemi EN, Gregori D, Berchialla P, et al. Epidemiology and risk factors for pathologic scarring after burn wounds. Archives of facial plastic surgery. 2008;10(2):93-102.

14. Lari AR, Alaghehbandan R, Nikui R. Epidemiological study of 3341 burns patients during three years in Tehran, Iran. Burns. 2000;26(1):49-53.

15. Al-Shehri M. The pattern of paediatric burn injuries in Southwestern, Saudi Arabia. West African journal of medicine. 2004;23(4):294-299.

16. Bang R, Mosbah K. Epidemiology of burns in Kuwait. Burns. 1988;14(3):194-200.

17. Hegazy M, Ibrahim E. The pattern and outcome of burn injuries at a burn unit in Saudi Arabia: Retrospective analysis of consecutive 501 patients. Annals of Saudi medicine. 1991;11(3):255-259.

18. Haberal M, Uçar U, Bilgin N. Epidemiological survey of burns treated in Ankara, Turkey and desirable burnprevention strategies. Burns. 1995;21(8):601-606. 